\title{
SEIS SONETOS DARWISHIANOS
}

\author{
Safa A-C. Jubran ${ }^{1}$ \\ Marco Antonio Calil Machado 1 \\ -1Universidade de São Paulo, São Paulo, São Paulo, Brasil
}

\begin{abstract}
Resumo: Este escrito terá por objetivo, pela apresentação da tradução a seis sonetos escritos por Mahmoud Darwish constantes no livro A Cama da Forasteira do ano de 1998, refletir acerca da questão do(s) soneto(s) darwishiano(s) contra o gesto, ou função-, soneto. Quanto à linguagem, em apresentando os poemas árabes vis-à-vis de suas contrapartes portuguesas, os sonetos serão comentados no que, em árabe, exibem de efeitos e efetividades linguístico-poéticas e como tais esquemas sonoros, semânticos, formais e discursivos possam ou não ser tra(du)zidos à língua portuguesa, levando em conta as implicações linguísticas, logo poéticas, da questão do gênero e número morfológicos, as figuras de duplos e o tema do Dois, tópico e típico do soneto qua gênero (textual).
\end{abstract}

Palavras-chave: Soneto; Poesia; Literatura; Mahmoud Darwish; Tradução

\section{SIX DARWISHIAN SONNETS}

\begin{abstract}
The purpose of this paper is, by presenting a translation to six sonnets written by Mahmoud Darwish in the 1998 book The Stranger's $B e d$, to reflect on the question of the Darwishian sonnet(s) against the gesture, or function, of the sonnet. As for language, in presenting the Arabic poems vis-à-vis their Portuguese counterparts, the sonnets will be commented on that which, in Arabic, exhibits linguistic-poetic effects and effectiveness insofar as such sonorous, semantic, formal and discursive schemes can or cannot be rendered in Portuguese, taking into account the linguistic and poetic implications of gender and morphological number, the figures of doubles and the theme of the Two, which is topic, typical to the sonnet qua (textual) genre.
\end{abstract}

Keywords: Sonnet; Poetry; Literature; Mahmoud Darwish; Translation 


$$
\text { ستّ سوناتات دروينبّة }
$$

يهدف هذا النص، من خحلال ترجمة ستّ من سوناتات محمود درويش الواردة في سربير الغريبة(1998)، إلى مناقشة موضوع

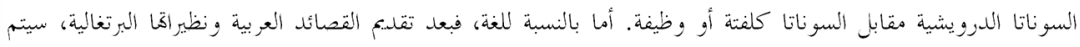

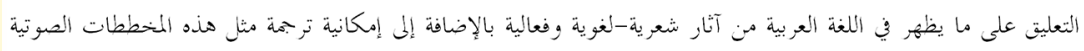

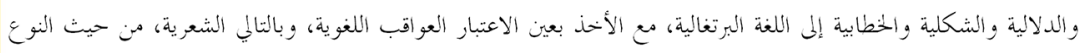

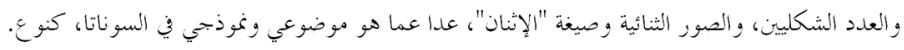

$$
\text { الكلمات الرئبسية: سوناتا؛ شعر؛ أدب؛ محمود درويش ؛ ترجمة }
$$

\section{El poeta pide a su amor que le escriba}

Amor de mis entrañas, viva muerte, en vano espero tu palabra escrita y pienso, con la flor que se marchita, que si vivo sin mi quiero perderte.

El aire es inmortal. La piedra inerte ni conoce la sombra ni la evita. Corazón interior no necesita la miel helada que la luna vierte.

Pero yo te sufrí. Rasgué mis venas, tigre y paloma, sobre tu cintura en duelo de mordiscos y azucenas.

Llena pues de palabras mi locura o déjame vivir en mi serena noche del alma para siempre oscura.

(Lorca 648) 


\section{Introdução}

\subsection{Do livro}

O livro A Cama da Forasteira compreende vinte e nove poemas dentre os quais esparsamente os seis sonetos se encontram. O motivo fundamental do livro é do encontro amoroso-erótico, do eu-e-tu, do masculino-e-feminino, da distância-separação-união. As figurações erótico-amorosas dos poemas, particularmente para uma certa fortuna crítica, vêm sendo, elas mesmas, simbolizadas em exílio palestino, isto é, o esquema de referências verbo-pronominais em seu aspecto número-genérico-pessoais (singular feminino) simboliza uma Palestina perdida e desejada, substantivo feminino singular em árabe. $\mathrm{O}$ tradutor estadunidense, em prefácio à tradução dos poemas de Darwish ao inglês, Fady Joudah, bem como Raed W. Jaradat, em artigo intitulado The Sonnet in the Modern Arabic Poetry, aventam a simbolização do ela-Palestina. Pretende-se preterir, para os efeitos daqui, as interpretações deriváveis deste percurso hermenêutico nos motivos globais do livro e dos sonetos: preferese, portanto, iniciar por algumas posições acerca do soneto, ao largo de uma exterioridade simbólica Palestina, restringindo-nos a uma análise da lírica-argumental, rente às maquinações-soneto.

\subsection{Dos sonetos do livro}

\subsubsection{Da presença- "Shakespeare”}

Três textos, aquele já mencionado de Jaradat, comentando a forma soneto em Darwish, outro de Muhammad Enani intitulado On Translating Shakespeare's Sonnets into Arabic, e a dissertação de mestrado de İmān Annizāmì acerca de $A$ Cama da Forasteira são nossa bibliografia de partida para o levantamento de dados em torno do que se disse do soneto (em) árabe. Os pesquisadores traçam, para a poesia moderna árabe, a presença autoral de 
Shakespeare, sobretudo seus sonetos e teatro, em adaptações em prosa. Há, em outros poemas de Mahmoud Darwish, menções ao dramaturgo-poeta elisabetano ( $c f$. o primeiro poema de $A$ Cama da Forasteira, Faltava-nos um Presente, bem como o poema posterior Não te desculpes pelo que fizeste, de livro homônimo, de 2003). Em que pese a presença shakespeariana na obra de Mahmoud Darwish, é indistinta a diferença entre o corpus teatral shakespeariano versus o corpus lírico: embora essa divisão responda ao revival pós-romântico e ao frisson autoral em torno de Shakespeare, não se sustentando por necessidade diante do corpus teatral shakespeariano ser ele próprio reconhecida e imanentemente poemático, a divisão entre presença teatral versus presença lírica pode ser produtiva e inscrever formas de leitura a mapear a função do soneto em Mahmoud Darwish e também, quiçá à moda especulativo-extrapolativa, a função-soneto em regiões da produção letrada e poemática árabe moderna. De qualquer forma, seja "Shakespeare" das Rimas, seja "Shakespeare" dos Dramas, Tragédias e Comédias, o Nome-do-Autor ou o índice "Shakespeare" ronda a poética darwishiana, propondo relações ainda a serem investigadas em outra parte e da parte de outrem: assim como a presença- "Shakespeare" tem sido avaliada em Machado de Assis, nos terrenos romanescos, ou mesmo, nos terrenos teatrais contemporâneos, em Sarah Kane, seria igualmente interessante avaliar a presença de Shakespeare desde a colonização inglesa sobre o mundo árabe, suas relações literárias e acomodações lexicais poético-tradutórias levadas em conta, como parece ocorrer nas elegias anglo-árabes de Fadwa Tuqan diante das elegias de William Blake, além do ousado contraste, proposto por Kamal Abu-Deeb em The Quest for the Sonnet - The Origins of the Sonnet in Arabic Poetry, em torno da forma soneto em sua configuração italiano-pré-petrarquiana com a مُوَنْنَ muwaššah andaluza. 


\subsubsection{Da forma-soneto}

Quanto ao soneto em sua dimensão estruturada sonora e semanticamente, isto é, quanto ao soneto em que pese sua poética, diverge de fato o soneto shakespeariano dos seis sonetos darwishianos. Primeiro, em seu aspecto gráfico: se os sonetos de Darwish exibem a organização editorial 4/4/3/3 versos, isso não responde ao soneto inglês elisabetano em suas configurações fac-similares (versos em 12/2 - exceto por um soneto darwishiano). Segundo, em seu aspecto métrico: os sonetos de Darwish não exibindo metro, não há coincidência com o iambo shakespeariano - ainda que, neste ponto, haja que se rever considerações de ritmo-rima para serem tratados esquemas sônicos anteriores ao colapso das disciplinas sonoro-musicais em sua dimensão esteticamente constrangida, pré-liberal - ao avesso de linhas de tratamento rítmico pós-modernas (isto é, para-a-instanciação-relativa-ao-Moderno), valéryanas ou messchonicianas, quais sejam. Terceiro, em seu aspecto lógico: a opacidade interpretativa mas estruturalmente binária do soneto darwishiano é contígua, ao menos em primeiro nível, ao caráter fundamentalmente argumentativo dos ciclos de soneto antigos. Tais três dimensões gráfica, métrica e lógica convocam, para um estudo mais aprofundado, disciplinas como a crítica textual, as tradições de edição do corpus shakespeariano lírico ou não, a história da literatura inglesa e sua circulação, a presença da literatura inglesa em colônias árabes, os estudos pré-romantizantes do soneto, de poética-retórica pré-românticas etc. Para os efeitos daqui, no entanto, restringir-se-á serem tecidos comentários em torno da dimensão gráfica, temática e lógica, daí temático-figurativa, dos seis sonetos de Mahmoud Darwish no ato de tradução.

Sejam, pois, os seis sonetos darwishianos listados abaixo em tabelas, soneto a soneto. 


\section{Corpus da tradução}

\section{(Darwish Sarīr alロarībah 16, 31, 42, 56, 71, 84)}

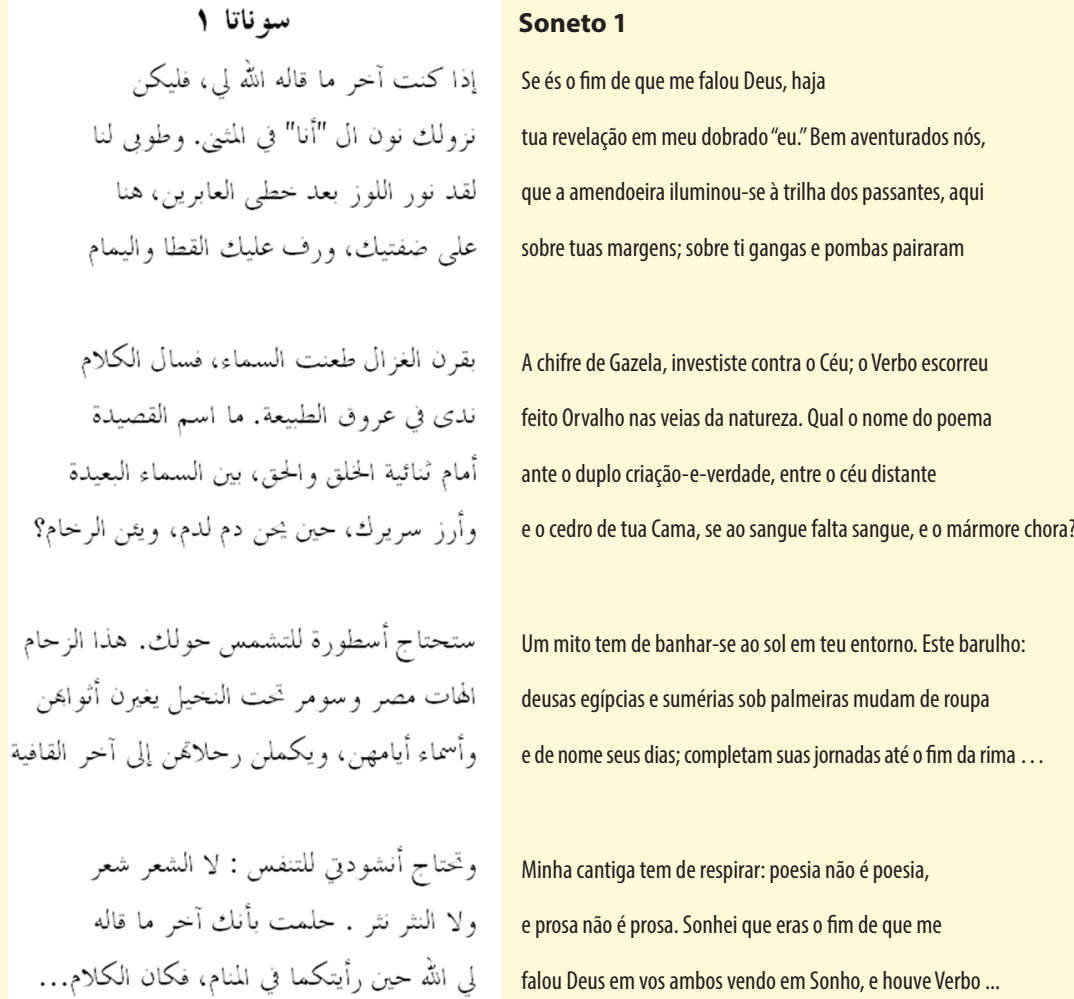




\section{Soneto 2}

Talvez se tornares tua sombra ao rio, não pedirás

do rio senão Mistério. Há um breve outono que

Salpica 0 corso a água de nuvem fugidia

Lá, no que nos deixaste de migalhas da viagem

غموضئك دُربكُ الحليب. غبارُ كواكبَ لا اسم لها

e Noite é teu Mistério em pérolas a iluminarem só a água,

Quanto ao Verbo, que ilumine a um único "Amo-te"

a noitedos migrantes entre dois Poemas Suspensos eduas folhas de palmeira

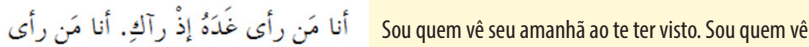

evangelhos escritos pelo último idólatra nos barrancos de Gileade

antes das antigas terras ou depois delas. Sou a nuvem retornada

à figueira cujo nome é o meu, feito a espada cujo rosto é do assassinado

Talvez, se tornares tua sombra a mim, confiras

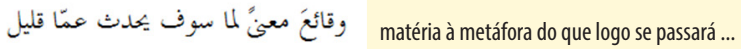




\section{Soneto 3}

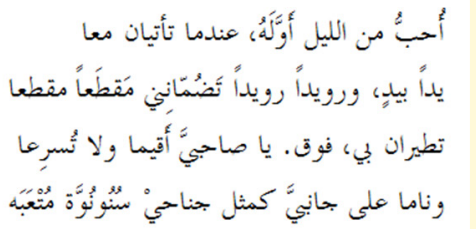

حريرُكما سانخِن. وعلى الناي أنْ يتأنَى قليلا

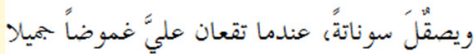

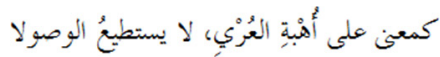

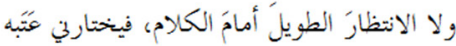

أُحبُِ من الشعر عَفْوِيَّة النثر والصورةَ المخافية بلا قمر للبازغة: حين تسيزين حافية" تتركُ القافية جماعُ الكالام، وينكسرُ الوَزْنُ في ذروة التجربة

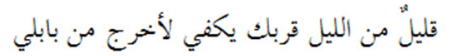
إلى جوهري - آنري. لا حديقة لي دانحلي

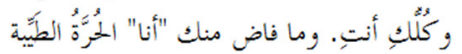

Amo da noite seu começo quando vindes ambos juntos mão em mão, pouco a pouco abraçais-me parte a parte e a mim me sobrevoais. Amigos, ficai, não vos apresseis e dormi aos meus lados como asas de andorinha exausta Ambas vossas sedas são quentes. A Flauta deve ser paciente e polir o soneto, quando me baixais feito Mistério, belos como 0 sentido prestes à nudez, incapaz da chegada e da longa espera frente ao Verbo, a escolher-me por limiar Amo da poesia 0 espontâneo da prosa e a imagem oculta sem lua à retórica: ao caminhares descalça, abandona a rima a cópula do Verbo, e o metro quebra no cume da experiência Um pouco de noite perto de ti basta-me para deixar minha Babilônia rumo à minha essência - meu outro. Não me há Jardim em mim e tudo teu és tu. 0 que te excede é "eu" livre, doce 


\section{Soneto}

Lento massageio teu Sono. Nome do que há em mim

de sonho, dorme. A noite ocluirá suas árvores, dormitará

em sua terra, mestre de breve ausência. Dorme que boiarei

em pontos de luz vazados da lua a qual incluo ...

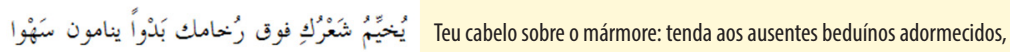

sem sonharem. Teu par de pombas iluminam-te desde os ombros

a teu Sono-Margarida. Dorme sobre ti e em ti. Sobre ti:

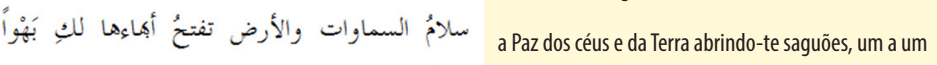

فبهوا

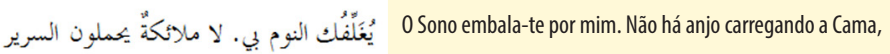

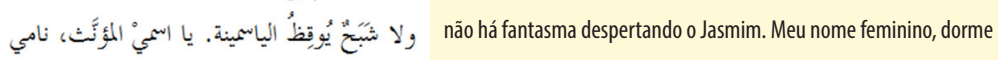

que não há Flauta chorando sobre a Égua fugida de minhas fendas

كما تحلمين تكونين، يا صيف أرضٍ شمالِّة

anestesiando suas mil florestas à presa do Sono. Dorme

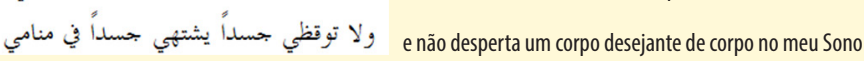




\section{• Soneto 5}

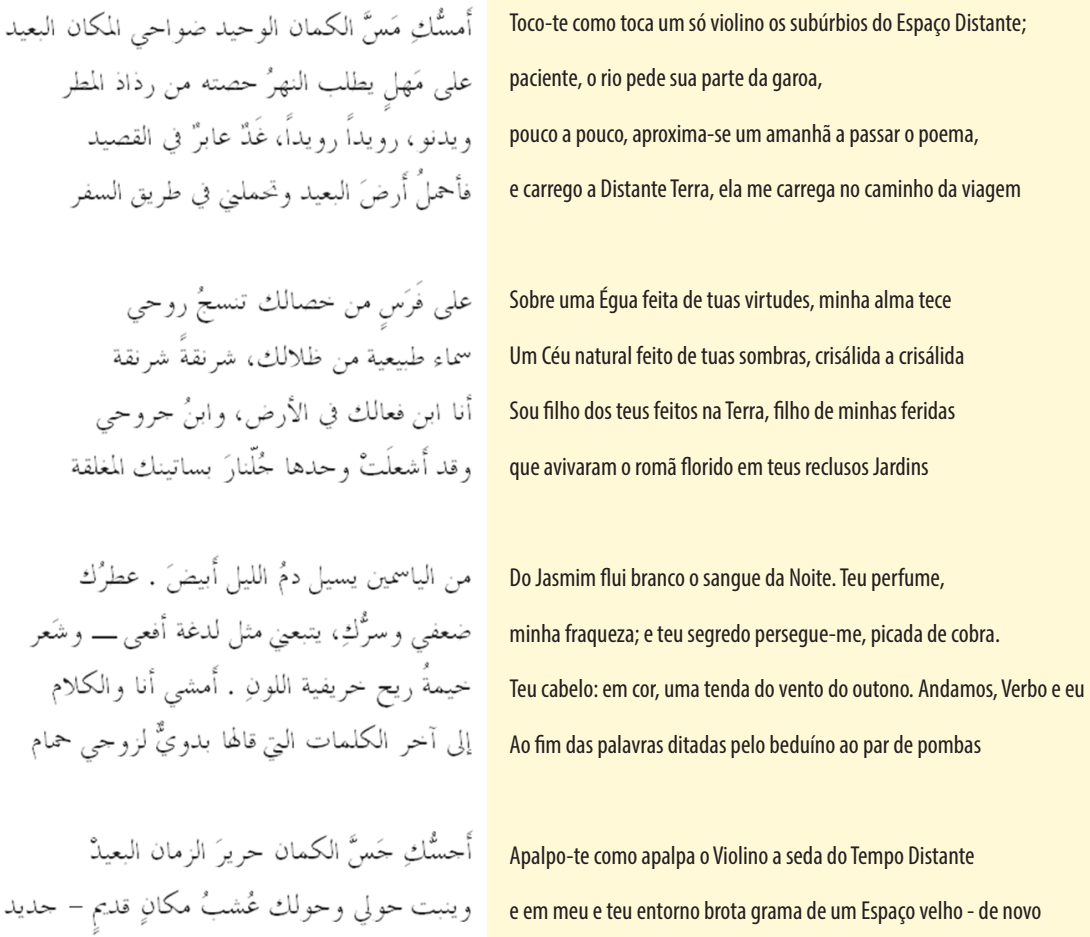




\section{Soneto 6}

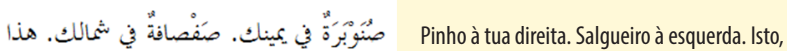

oVerão: uma das cem Gazelas tuas rendeu-se ao Orvalho

e gdormiu em meu ombro, perto de uma de tuas regiões, mas e

Se olobo notar, e se o bosque ao longe se incendiar?

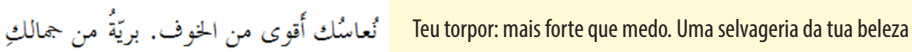

dormita, e desperta uma lua de tuas Sombras para guardar suas árvores.

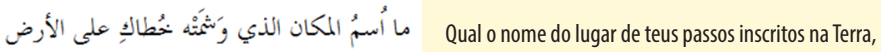

Terra Celestial à Paz de pássaros próximos ao eco?

و وأقوى من السيف نومُكك بين ذراعيك مُنسابَتين

como dois rios, no paraíso do sonhador, do que fazes nos dois bancos

por conta e sobre ti própria. 0 lobo talvez carregue uma Flauta

e pelo rio chore: 0 que não se efemina ... é em vão

Um pouco de fraqueza na metáfora basta, amanhã,

para as amoras amadurecerem na cerca; para a espada rachar sob o Orvalho

\section{Breve comentário tradutológico}

\section{Da tradução dos seis sonetos}

Acerca da tarefa de tradução dos seis sonetos darwishianos, cabe comentá-las, tradução e tarefa, no que, desde a língua árabe padrão até a língua portuguesa, deu-se de correspondências e incorrespondências; de equivalências linguísticas mais ou menos imediatas, mais ou menos mediatas. A este respeito, a tradução, desde o duplo sentido de tração e de deslocamento entre as duas línguas em questão, bem como desde a dupla mirada (fundacional, e aqui operacional) da forma versus conteúdo, dobrou questões quanto à passagem interlinguística dos marcadores pronominais (seção 2.1) 
e quanto à formação de um padrão lexical autorreferido (seção 2.2), acarretando questões grosso modo discursivas ao soneto em que pese sua movimentação interna, isto é, suas maquinações.

\subsection{Do sistema pronominal}

Acerca do sistema pronominal em tradução, serão perspectivadas em separado, ainda que constitutivamente interdependentes, as ocorrências pronominais ao domínio dos pronomes verbais, presos à conjugação modo-pessoal da língua árabe padrão, e as ocorrências pronominais no domínio dos pronomes livres e/ou clíticos, presos à função nominal como possessivos ou marcadores pessoais enuncivo-enunciativos.

A bem saber, trata-se prioritariamente:

a. dos transmorfemas verbais de segunda pessoa feminina sin-

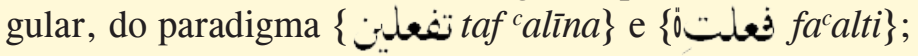

b. do transmorfema verbal de segunda pessoa plural-dual, do paradigma $\{$ ive taf calāni\};

c. do pronome oblíquo de segunda pessoa feminino singular $\{\underline{s}--k a\}$, relativo ao pronome livre pragmaticamente derrubado $\{\underbrace{\mid}$ anti $\}$

d. do pronome oblíquo de segunda pessoa plural-dual كمكاك-kumā $\}$, relativo ao pronome livre pragmaticamente derrubado $\{$ iأنسا antuma $\}$.

e. As ocorrências em a) e c) constituem um eixo transversal às em b) e d), sendo o ponto de encontro delas analisado ao longo do artigo em suas dimensões tradutórias e poéticodiscursivas.

\subsubsection{Do sistema verbo-pronominal, ou Da interpelação}

A maneira pela qual os verbos árabes do soneto se organizam marca ostensivamente a interpelação desde um "eu” (Iن̉anā) a um 
"tu" (vide traduções no corpus e seção 2.1); os seis sonetos darwishianos priorizam a evocação discursiva explícita de um "tu," por vezes "vós" (vide Soneto 3). O inventário de oposições estruturais dos paradigmas verbais em árabe padrão, em que pese a ocorrência de formas de gênero feminino e número dual para os referentes interpelados pela morfologia da conjugação verbal, impõe, na tradução e com fins de escrutabilidade referencial, o emprego de formas número-pessoais do português padrão ("tu" e "vós"). No entanto, não obstante arcaizantes e/ou inusitadas, tais formas prestam a precisar as referências de número, falhando na imagem feminina do interlocutor na própria morfologia do verbo português vis-à-vis a língua árabe. Trata-se, portanto, de uma restrição no inventário genérico-numérico-pessoal do sistema linguístico do português: a constância e o escopo em operação pelos transmorfemas femininos e duais não se podem expressar plenamente em "tu" e "vós," que não guardam nem traço morfossemântico de gênero, nem de número-dual.

A neutralização da forma pela qual o interlocutor (feminino singular, por vezes dual) é categorizado em árabe e reconfigurado na tradução recupera a questão do gênero morfológico, do acarretamento poético-retórico, bem como do hiperacarretamento erótico-sexual derivado, por exemplo, nos marcadores discursivos de número e pessoa no corpus shakespeariano de sonetos. A este respeito, em introdução à edição crítica aos sonetos de Shakespeare, Orgel comenta:

The Sonnets include no record of the effect of this revelation on the beautiful young man, but it changes nothing in the progress of the love: the beloved remains perfectly narcissistic, the poet hopelessly infatuated. Ingles and kept boys - and, for the most part, sexual satisfaction, whatever the gender of the beloved - belong to the world of comedy, not to the world of the Sonnets. [...]

A letter written by King James to his favourite Duke of Buckingham gives a good sense of how much the homoerotic was part of the currency of social relationships in Shakespeare's age. [...]

The rhetoric of patronage, and of male friendship generally, 
was precisely the language of love, and it rendered all such relationships literally ambiguous. Such language does not necessarily imply a sexual relationship; but it is important to add that, by the same token, nothing in the language precludes it either. [...] The language of love in the age implies everything but tells nothing. (Orgel 15-16)

Isso ocorre justamente por causa do sistema neutro de gênero morfológico em inglês, recaindo o gênero da palavra sobre sua semântica referencial e convenções pronominais, lado a lado dos dispositivos retórico-poéticos, lógico-representacionais à época. Ainda que tal consideração não seja um problema de tradução stricto sensu por se tratar da língua inglesa pela língua inglesa, pode-se derivar daí uma questão em torno da força da arbitrariedade e convencionalidade do sistema pronominal (ou sua generalidade do ponto de vista linguístico-analítico), em supondo a estabilidade e presença da deixis de "pessoa" para toda e qualquer língua. Ora, se é justamente (relativa ao árabe e ao português) por sobre a pobreza gênero-pessoal da língua inglesa que se pode gerar uma simulação flutuante do naked boy até a mysterious dark lady, bem como se pode hipo- ou hiperinflacionar tal imago em a obliterando ou a estimando, é justamente, e ao contrário, por sobre a exuberância número-genérico-pessoal do sistema pronominal da língua árabe padrão que se gera uma imago, desta vez ao menos composicionalmente, discrecionada, isto é, pesadamente investida nos jogos de referência pelo número e gênero linguísticos.

É, enfim, por sobre tal discrição do ethos do interlocutor que recai o jogo masculino-feminino, singular-plural, eu-e-tu, bem como o colapso dessas cisões, do qual comentaremos a seguir, nos sonetos darwishianos em particular, bem como em outros poemas mais amplamente: para tanto, vide, de Darwish, Canção de Casamento, Serás esquecido como se não tivesses sido, $A$ esperar etc. 


\subsubsection{Do sistema nominal-pronominal, ou Da duplicação}

A maneira pela qual nomes e pronomes livres ou clíticos são marcados indica ostensivamente a situação desde "eu" a um "tu" feminino, o que acarreta, observado para os pronomes em conjugação verbal, a anatomia de pronomes livres ou presos aos nomes ser transversal à outra, verbo-pronominal. Curiosamente, nessa dimensão nominativa, por assim dizer, dos pronomes, há uma ocorrência digna de menção à parte.

Os seis sonetos constroem, pela expressiva morfologia template cacofônica e combinatória da língua árabe, uma propriedade poético-semiótica dos termos gramaticais para a categoria morfológica

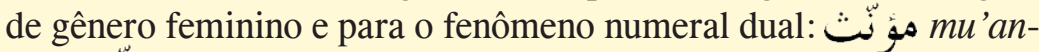

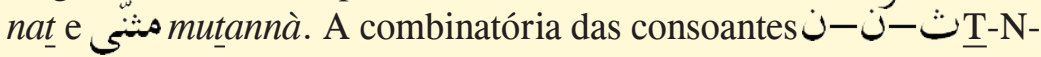
-N, interpretáveis como "dois" ou "feminino" em língua portuguesa, explora a dinâmica da morfologia template semítica: se isso remonta genealógica ou etimologicamente a uma coincidência entre a noção de "feminino" como uma operação matricial de base dois, ao menos do ponto de vista icônico, a efetividade pela conveniência e felicidade dessa etimologia é ímpar, o que bloqueia, no ato de tradução para o português, a transparência do próprio jogo com a raiz consonantal e regras de formação.

"Feminino" e "duplo/dois/dual" projetam, nesse sentido, um jogo limite: deste equacionamento "feminino = duplo" e dos ecos, rimas (internas) e perífrases por semelhança sonora e contiguidade semântica, estabelece-se um campo metafórico em ritornello. Disso, então, gera-se circularidade entre os valores do femininomasculino, eu-lírico e interlocutor, eu-e-tu, de modo a colapsar a distância entre os termos: se os poemas começam pela dualidade da cisão, não terminarão nela. Tal processo recupera centralmente o esquema argumentativo binário e dialético do soneto, que o estrutura como máquina conceitual; à guisa de comparação, basta recuperar o abstrato jogo do Dois (isto é, uma ob-posição fundamental, ainda que modalizada por figuras semióticas distintas) em Camões Mudam-se os tempos, mudam-se as vontades e Transforma-se o 
amador na cousa amada, de Petrarca Mille fiate, o dolce mia guerrera e Piovonmi amare lagrime dal viso, de Shakespeare o soneto 127 In the old age black was not counted fair e de Lorca o exemplarmente reduplicante, antitético e aqui epigráfico El Poeta pide a su Amor que le escriba. Nesse ponto, os seis sonetos darwishianos são uma emulação fortíssima do gênero soneto, aproveitando das operações morfológicas combinatórias da raiz $-ن-ن-N-N$ e do duplo de sua anfibolia para potencializar a expressão dos nexos e colapsos dos duplos típicos e tópicos da lírica amorosa de soneto. Tal iconismo linguístico-estrutural para a operação em conceitos binários nos sonetos encontra dimensão maximizada pelo primeiro poema (Darwish 9) do livro A Cama da Forasteira:

$$
\begin{aligned}
& \text { Somos gentis aqui. Boreal, } \\
& \text { nosso vento; nossas cançôes, austrais. } \\
& \text { هل أنا أنت }
\end{aligned}
$$

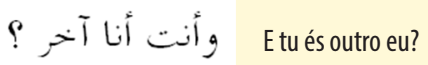

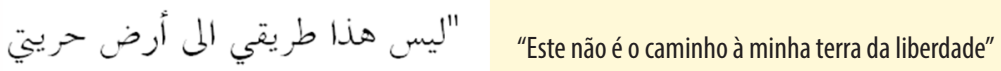

$$
\begin{aligned}
& \text { este não é o caminho ao meu corpo } \\
& \text { e enão serei "eu" duas vezes } \\
& \text { وقا حل أصس محل غناي agora que meu ontem deveio meu amanhã } \\
& \text { gedividi-me em duas mulheres; } \\
& \text { فال أنا شرقية portanto não sou oriental, }
\end{aligned}
$$

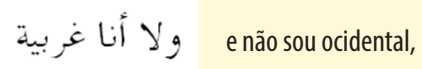

$$
\begin{aligned}
& \text { e nem sou uma oliveira sombreando dois versos corânicos: } \\
& \text { entãovamos. }
\end{aligned}
$$




\subsection{Do léxico, ou Da nomeação}

A maneira pela qual os sonetos distribuem certos nomes marca um conjunto lexical de potencialidades conceptuais (uma terminologia), grafado, na tradução portuguesa, por letras maiúsculas: trata-se das oposições de palavras que soem repetirem-se e (res)soem entre si. Se esse processo grafemático-conceptual, disponível a um sistema de escrita de base fonético-fonêmica como o latino também se expressa, por exemplo, na lírica camoniana com "Amor", "Ceo[s]", "Deos" etc., parece que, no caso dos sonetos darwishianos, os conceitos em jogo não exibem a mesma transparência simbólica e expressão de tradição tipográfica como "Amor", "Ceo[s]" ou "Deos," em letras capitais. O léxico conceptualizado, são só pela repetição de termos ao longo dos seis sonetos mas também ao largo dos livros pós-1990, acaba por gerar uma outra redundância no nível da palavra, configurando-se, portanto, como jogos de palavras (t)autorreferenciais, produtores de uma opacidade simbólica e de uma microplataforma de (t)autorreferências, metáforas localizadas, limiares etc.

Nesse sentido, parece tratar-se de um encontrar-palavras pela primeira vez, encontrar em meu e teu entorno [a grama que brota] de um Espaço antigo - de novo (Soneto 5), de modo que, em procurar-e-encontrar os meios da canção, pelos quais ela respire (Soneto 1), paradoxalmente o dito possa ser arbitrado, isto é, arbitrário, como nos versos (Darwish Sarīr al】arībah 11):

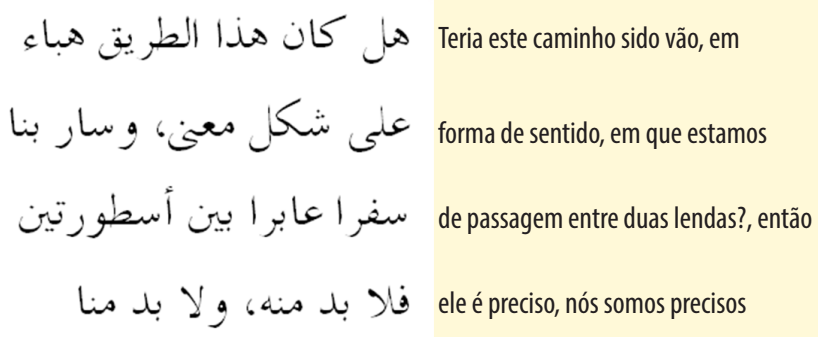

Cad. Trad., Florianópolis, v. 39, nº esp., p. 259-279, set-dez, 2019 
O jogo, in situ \& ad usum dos próprios poemas, de instituição de uma dimensão conceptual-simbólica e hesitação do significado como transparência configura, portanto, um plano de checagem do sentido, isto é, uma decisão de nomeação imanentemente criativa pelo $e$ desde o lastro ou o eco de um certo sentido que se faça, desfazendo-se. Em suma, tal estratégia semiótica parece ser uma constante em poemas darwishianos pós-1990, culminando na radical opacidade de $\mathrm{Na}$ [ou Da] Presença da Ausência, exemplar, outrossim, no poema que se presta a descrever a gênese da nomeação, como nos versos (Darwish Là ta'tadir 101-102):

$$
\begin{aligned}
& \text { لا لأعرف فيملكِ Não sei teu nome } \\
& \text { Chama-me como queiras } \\
& \text { Não és Gazela } \\
& \text { Não, nem mesmo Égua } \\
& \text { E Eão és a Pomba do Exílio } \\
& \text { و و لا مورية" Nem Sereia } \\
& \text { من أنتِِ؟ ما اسملكِ؟ } \\
& \text { Nomeia-me que serei o que me nomeares } \\
& \text { Não posso, que sou vento } \\
& \text { e és forasteira como eu, os nomes tendo terras }
\end{aligned}
$$

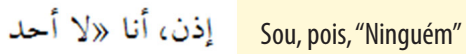

$$
\begin{aligned}
& \text { Não sei teu nome, qual teu nome? } \\
& \text { Escolhe dentre os nomes o mais próximo } \\
& \text { do Esquecimento. Nomeia-me que serei } \\
& \text { nesta noite o que me nomeares } \\
& \text { Não posso, que sou mulher viajante } \\
& \text { no vento. Eés viajante como eu, }
\end{aligned}
$$




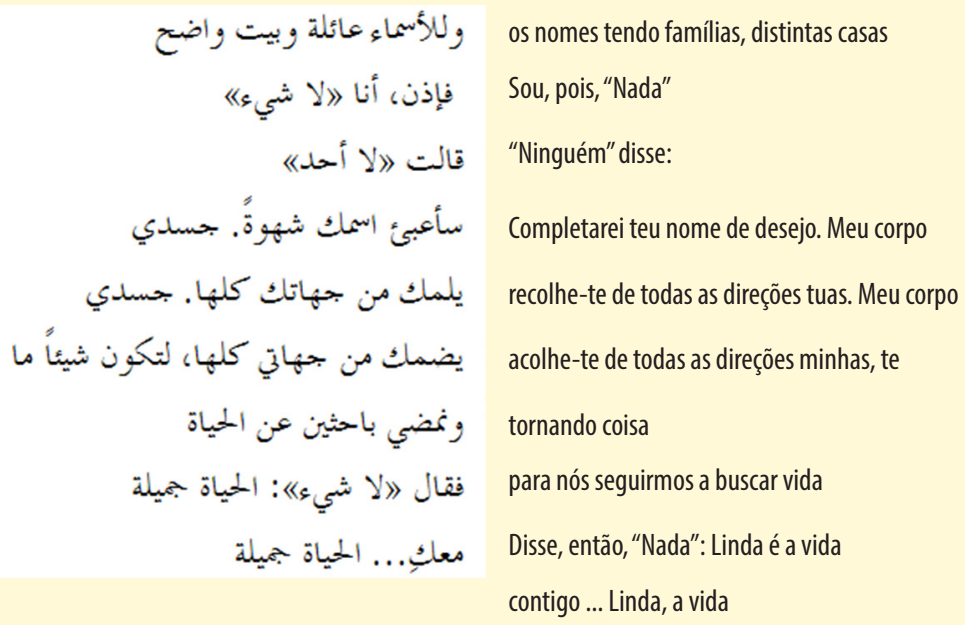

\section{Conclusão}

\subsection{Do fim, ou Da interpretação}

Tencionou-se aqui apresentar e comentar a tradução de seis sonetos escritos por Mahmoud Darwish, constantes no livro A Cama da Forasteira do ano de 1998. Quanto à linguagem, apresentados os originais árabes vis-à-vis suas contrapartes portuguesas, os sonetos foram comentados no que, em árabe, exibem de efeitos e efetividades linguístico-poéticas e como tais esquemas sonoros, semânticos, formais e discursivos, derivados sobretudo do sistema pronominal no jogo de interpelação dos sonetos, possam ou não ser tra(du)zidos à língua portuguesa. O tema geral amoroso e erótico na interpelação, ecos do jogo de ligação amorosa da antiga poesia de nasīb, quer-nos parecer, não se adequa à forma pela qual o erótico-amoroso nos sonetos simbolizam o exílio palestino, isto é, o esquema de referências verbo-pronominais em seu aspecto número-genérico-pessoais (singular feminino) qua Palestina, substantivo feminino singular em árabe. 
Quanto aos seis sonetos em sua dimensão estruturada, isto é, quanto aos sonetos em que pese sua poética, ainda que divirjam de fato do soneto shakespeariano ou petrarquiano como prototipos, há uma forte imitação-emulação da função-soneto em sua lógica, ou estrutura de oposições, ou seja, dialética. Não somente em relação ao aspecto gráfico e à atmosfera rítmica, há uma arquitetura argumentativa-em-dois que, embora opaca na dimensão figurativa nos sonetos darwishianos, se se opõem ao menos em primeiro nível ao caráter clara e abertamente argumentativo do soneto como gênero filosofante, em um segundo nível coincidirão com a lógica cripto -erótica (porque investida da criptologia de expressões distantes, alfā̄ $b a^{c} \overline{1} d a$ ) do Dois-em-Um e dialético-dual, partilhado aos antigos ciclos de sonetos. O léxico conceptualizado e o jogo opositivo de metáforas derivadas, por estarem em ritornello ao longo dos seis sonetos mas também ao largo da lírica final de Darwish, acabam por gerar uma outra redundância a nível discursivo, configuradas, portanto, como jogos (t)autorreferenciais. Disso, então, geram-se reenvios e curto-circuitos entre os valores do feminino-masculino, eu-lírico e interlocutor, eu-e-tu, de modo a colapsar a distância entre tais parâmetros: se os poemas começam pela dualidade da cisão, não terminarão nela. É por via dessa dimensão de movimento de duplos recombinantes e mutuamente aniquiladores (uma síntese das antíteses...) que os seis sonetos recuperam centralmente o esquema argumentativo binário e dialético do soneto, que os estrutura como máquina conceitual, em última instância estereológica.

\section{Referências}

Darwish, Mahmoud. Lā tactadir 'amma facalta. Jordânia: Dar Al Nashir \& AlAhliyya, 2013. 
Darwish, Mahmoud. Sarīr alġarībah. Jordânia: Dar Al Nashir \& Al-Ahliyya, 2014.

Lorca, Federico García. Obra Poética Completa. São Paulo: Editora UnB, Imprensa Oficial, 2004.

Orgel, Stephen. Introduction. In: Shakespeare, William. Evans, G. Blakemore, editor. The Sonnets. Cambridge: Cambridge University Press, 2012.

Recebido em: 15/09/2019

Aceito em: 12/11/2019

Publicado em dezembro de 2019

Safa A-C. Jubran. E-mail: sjubran@usp.br.

ORCID: https://orcid.org/0000-0002-1117-5995.

Marco Antonio Calil Machado. E-mail: marco.calil.machado@usp.br

ORCID: https://orcid.org/0000-0003-3273-9910

Recebeu financiamento pela CAPES para Mestrado, entre os anos 2018-2019.

Cad. Trad., Florianópolis, v. 39, nº esp., p. 259-279, set-dez, 2019 